\title{
Hábeas corpus contra resoluciones judiciales penales en el Código Procesal Constitucional ${ }^{*}$
}

Javier A. Aguirre Ch.*

\section{Introducción}

La libertad personal es un derecho fundamental que se encuentra por encima de los demás derechos. El derecho a la libertad personal garantiza la realización de un proyecto de vida acorde con los propios intereses, permite la realización plena del ser humano y, por ende, es la base sobre la cual descansan los demás derechos, con excepción del derecho a la vida. No puede existir el derecho a la intimidad si el sujeto, en el pleno ejercicio de su libertad personal, no ha desarrollado determinados actos que constituyen su esfera intima (personal o familiar); asimismo, no puede existir el derecho al honor y la buena reputación si el sujeto, en el ejercicio pleno de su libertad personal, no ha desarrollado determinados actos que le permiten tener autoestima o la apreciación de los «otros»; como se puede apreciar en estos dos ejemplos, la libertad personal se constituye en el derecho fundamental por excelencia.

No obstante la trascendencia del derecho a la libertad personal, este, per se, no se encuentra protegido de cualquier acto que lo pueda vulnerar, amenazar o limitar. En efecto, es cotidiano observar la vulneración, amenaza o limitación de este derecho, sea por actos de un particular, una autoridad o un funcionario.

Para la elaboración de este artículo, se contó con la valiosa colaboración de Heinz J. Cieza R., abogado por la Universidad Nacional Mayor de San Marcos, quien ejerce la profesión en el Estudio Aguirre, Abogados.

** Abogado por la Pontificia Universidad Católica del Perú. Agente titular del Estado peruano ante la Corte Interamericana de Derechos Humanos. Socio principal del Estudio Aguirre, Abogados. 
Si bien es cierto que la libertad personal no es absoluta, pues encuentra su límite justo donde empieza el derecho de «los demás», sin embargo, incluso cualquier acto que atenta contra los derechos de "los demás» no necesariamente es causa o motivo suficiente para privar de la libertad personal al autor de tal acto.

Constitucionalmente solo se puede privar de la libertad personal, sin que esta sea arbitraria o ilegal, en dos supuestos: 1) por la autoridad policial en caso de flagrante delito o 2) por mandato escrito y motivado del juez. Fuera de los límites de estos dos supuestos, cualquiera sea el motivo o la razón, la privación de la libertad personal constituye un acto ilegal o arbitrario.

Esta afirmación supone que toda forma de privación de la libertad personal en esos dos supuestos es legal. Pues bien, la jurisprudencia y el nuevo Código Procesal Constitucional (CPCL) ${ }^{1}$ nos permiten afirmar lo contrario: la privación de la libertad personal mediante mandamiento escrito y motivado del juez también puede ser arbitraria y/o ilegal.

Frente a esta situación, se ha creado un instrumento constitucional, cuya utilidad se explota en términos jurídicos, únicamente frente a la privación de la libertad personal por actos arbitrarios o ilegales, actos que, incluso, pueden emitirse dentro de un proceso judicial; nos referimos, como es obvio, al proceso constitucional de hábeas corpus.

Las líneas siguientes no tienen por objeto referirse a todos los supuestos de privación de la libertad (v. gr., por actos de particulares, por funcionarios de la Policía, en los regímenes de excepción, etc) de manera arbitraria o ilegal; sino solo pretendemos una aproximación a la nueva regulación que ofrece el CPCL sobre el hábeas corpus frente a la vulneración, amenaza o limitación de la libertad personal dentro de un proceso judicial penal.

\section{El hábeas corpus contra resoluciones judiciales en la ley 23506 y su ley complementaria, la ley 25398}

\section{Proceso regular y proceso irregular}

\section{i. Aproximación conceptual}

El artículo 6, inciso 2, de la ley 23506 señalaba que «no proceden las acciones de garantía [...] contra resolución judicial o arbitral emanada de

Publicado en el diario oficial El Peruano el 31 de mayo de 2004, en el boletín de normas legales de la p. 269424 a la 269436. 
un proceso regular». Asimismo, el artículo 10 de la ley 25398 decía lo siguiente:

Las anomalías que pudieran cometerse dentro del proceso regular al que se refiere el inciso 2 del artículo $6^{\circ}$ de la Ley [se refiere a la ley 23506] deberán ventilarse y resolverse dentro de los mismos procesos mediante el ejercicio de los recursos que las normas procesales específicas establecen. No podrá bajo ningún motivo detenerse mediante una acción de garantía, la ejecución de una sentencia contra la parte vencida dentro de un proceso regular.

Si bien la ley hacía una mención al "proceso regular», sin embargo, no lo definía, con lo cual quedó el campo abierto para que la jurisprudencia y la doctrina delimiten dicho término otorgándole un contenido específico.

En efecto, en primer lugar, se entendió que, si bien no procede el hábeas corpus contra una resolución judicial emanada de un proceso regular, en una interpretación a contrario sensu, sí procedía contra una resolución judicial emanada de un proceso irregular.

Pero ¿qué se entiende por proceso regular o proceso irregular? Al respecto, Guillermo Cabanellas ${ }^{2}$ señala que el término regular es un vocablo polifacético cuyo significado es «con arreglo a regla, reglamentario, normal». El mismo Cabanellas, ${ }^{3}$ en una aproximación más concreta a los términos que utilizaba la ley, expresa que el término proceso anormal se refiere a "toda tramitación en que no se observen las reglas del procedimiento, y siempre que la parte por ello perjudicada proceda a la impugnación pertinente para restablecer la normalidad en los trámites».

Equiparando los términos proceso anormal y proceso irregular, tenemos que este se define como aquel en el que no se observan las reglas del procedimiento, es decir, un proceso que "no se arregla a la regla».

No obstante ello, es evidente que la definición de proceso irregular es muy amplia; en efecto, en sus límites se encuentran todo tipo de inobservancia de reglas del procedimiento, por mínimas que estas sean. Así, tenemos que un simple defecto en la notificación es producto de una inobservancia de las reglas de procedimiento, por citar un ejemplo.

\section{ii. Proceso irregular en el que procede el hábeas corpus}

Ahora bien, el hábeas corpus no puede ser utilizado frente a cualquier anomalía o irregularidad que se suscite; es decir, no puede ser el instrumento

CABANELlas, Guillermo. Diccionario enciclopédico de derecho usual. 24. ${ }^{a}$ ed. T. VII. Buenos Aires: Heliasta, 1996, p. 109.

Ib., t. vI, p. 437. 
jurídico reemplazante de los medios impugnatorios propios que existen dentro de todo proceso judicial. De ser así, el proceso constitucional de hábeas corpus se convertiría en una especie de proceso constitucional especial para revisar cualquier resolución judicial.

Luis R. Saénz Dávalos ${ }^{4}$ nos dice que

[...] en efecto, la irregularidad o simple anomalía procesal, como lo podría ser un proveído incorrecto, una equivocada notificación, la inobservancia de un plazo no gravitante, es esencialmente un error judicial de poca o escasa trascendencia. Su sola presencia, bien que incorrecta, no afecta sin embargo el resultado del proceso, pues no tiene mayor incidencia o repercusión a los efectos de considerarlo como auténticamente justo. Por lo mismo la anomalía o simple irregularidad procesal, no puede catalogarse como directamente inconstitucional [...]. Sí, las anomalías, en otras palabras se corrigen mediante los recursos o mecanismos internos, el procedimiento irregular requerirá en cambio, de otro tipo de mecanismos [el subrayado es nuestro] .

Por consiguiente, la simple anomalía no puede catalogarse como directamente inconstitucional; contrario sensu, habrá que encontrar, dentro de un proceso judicial, una anomalía directamente inconstitucional para ser catalogado como irregular para los efectos del hábeas corpus.

Ahora bien, una anomalía directamente inconstitucional, como bien lo ha entendido la doctrina y la jurisprudencia, solo puede ser aquella que vulnera las garantías constitucionales mínimas que se deben observar en el transcurrir de un proceso judicial.

En reiterada jurisprudencia,

[...] para el Tribunal Constitucional, el concepto de "proceso regular», como supuesto de improcedencia del habeas corpus contra resoluciones judiciales, está inescindiblemente ligado al desarrollo normal y respeto escrupuloso de los derechos de naturaleza procesal: el de tutela jurisdiccional efectiva y el debido proceso [el subrayado es nuestro] y, con ellos, todos los derechos que lo conforman. ${ }^{5}$

El distinguido constitucionalista Francisco José Eguiguren Praeli, ${ }^{6}$ comentando la jurisprudencia del Tribunal Constitucional, señala que,

[...] no obstante, la legislación de la materia precisa que tales acciones no serán viables contra las resoluciones judiciales «emanadas de un proceso regular»,

Sáenz dávalos, luis R. "Los Procesos Constitucionales como mecanismos de protección frente a resoluciones judiciales arbitrarias». En Susana Castañeda Otsu (coord.). Derecho Procesal Constitucional. 1. ${ }^{a}$ ed. Lima: Jurista Editores, 2003, pp. 138-139.

5 En <http://www.tc.gob.pe/jurisprudencia/2002/1230-2002-HC.html>.

6 En <http://www.scielo.cl/scielo.php?pid=S0718-001223000100009\&script=sci_arttext\&tlng=es>. 
concepto que la jurisprudencia ha buscado establecer señalando que no cualquier vicio al interior de un proceso «regular» le hace perder dicho carácter, sino aquellas vulneraciones graves que afectan un derecho constitucional, especialmente en lo referido a la observancia del debido proceso y el respeto a la tutela judicial [el subrayado es nuestro].

En esa misma línea, Eloy Espinoza-Saldaña Barrera ${ }^{7}$ expone que

[...] es doctrinariamente con valiosos trabajos [...] que va determinándose que un proceso es regular cuando respeta el derecho de acceso a la justicia y las garantías de un debido proceso [...]. El desarrollo doctrinario primero, y jurisprudencial después, va progresivamente apuntalando la idea de que la regularidad de un proceso está vinculada a su respeto a la tutela judicial efectiva (entendida en el Perú por nuestro Tribunal Constitucional como derecho de acceso a la justicia, y además, como la necesidad de asegurar la efectividad de las resoluciones judiciales) y, fundamentalmente, al debido proceso [el subrayado es nuestro].

Tal como se puede apreciar, tanto la doctrina como la jurisprudencia se encargaron de brindar un concepto de lo que debe entenderse por proceso regular a efectos de la interposición del proceso constitucional de hábeas corpus. El concepto del mismo quedó delimitado por el respeto escrupuloso de las garantías constitucionales al debido proceso legal y la tutela judicial efectiva. En buena cuenta, se establece que, desde la óptica constitucional, todo proceso judicial penal (para efectos de este artículo), en el que se respeten ambas garantías, es un proceso regular.

En consecuencia, un proceso irregular — susceptible de ser «reparado» por el proceso constitucional de hábeas corpus - es aquel que vulnera uno y otro derecho de manera conjunta o alterna, siempre y cuando, al mismo tiempo, vulnere la libertad personal del imputado.

\section{iii. Debido proceso legal y tutela judicial efectiva}

No es objeto del presente trabajo realizar un estudio profundo sobre uno y otro derecho, si constituyen un solo derecho o ambos son diferentes; solo pretendemos anotar el contenido de los mismos a fin de tener una idea más exacta de lo que regula actualmente el CPCL.

Para Aníbal Quiroga León, ${ }^{8}$ el debido proceso legal es

En <http://www.justiciaviva.org.pe/publica/03.pdf>.

8 Quiroga LeÓN, Aníbal. El debido proceso legal en el Perú y el sistema interamericano de protección de derechos humanos. Lima: Jurista Editores, 2003, p. 47. 
[...] la institución del Derecho Constitucional Procesal que identifica los principios y presupuestos procesales minimos que siempre debe reunir todo proceso judicial jurisdiccional para asegurar al justiciable la certeza, justicia, razonabilidad y legitimidad de resultado socialmente aceptable [la cursiva es nuestro].

\section{Por igual derrotero, Susana Castañeda Otsu ${ }^{9}$ expresa que}

[...] otro derecho que no aparece en el listado enunciativo del art. $12^{\circ}$ de la Ley $\mathrm{N}^{\circ}$ 23506 es el debido proceso. Esta omisión no implica que el habeas corpus no pueda ser utilizado para atacar resoluciones que emanen de un proceso que no ha tenido en consideración el respeto de los estándares mínimos que integra este derecho macro, denomina debido proceso [la cursiva es nuestra].

Estos autores coinciden en señalar que el debido proceso legal engloba aquellos principios o derechos minimos que se deben observar en la tramitación de un determinado proceso judicial a fin de que este pueda garantizar la realización efectiva de un determinado derecho sometido a la administración de justicia dentro de los parámetros de razonabilidad, proporcionalidad y justicia. ${ }^{10}$

En un proceso judicial, cualquiera sea la naturaleza de la pretensión por la cual se accede al mismo, en última instancia, se constituye en el cause por donde discurre una «contienda» jurídica, en la que, al término del mismo, se plasmará la realización efectiva de un determinado derecho.

Así, por ejemplo, en un proceso penal, existe una "contienda» jurídica en la que, por un lado, se pretende la realización del derecho de sancionar del Estado y, por el otro lado, se pretende la realización del derecho a la libertad personal del imputado. Es evidente que la_vulneración a los estándares minimos del cauce por donde discurre dicha contienda podría vulnerar, amenazar o limitar la libertad personal del procesado; he aquí la justificación

Castañeda Otsu, Susana Inés. "Hábeas Corpus. Normativa y Aspectos Procesales». En Susana Inés Castañeda Otsu (coord.). Op. cit., p. 307.

10 Al respecto, MARCELO DE BERNARDIS, Luis. La garantía procesal del debido proceso. Lima: Cultural Cuzco, 1995, p. 331, dice: "Como quiera que la actividad jurisdiccional tiene por objeto principal determinar la justicia del caso concreto, las reglas establecidas para tal objeto no podrán dejar de contener los instrumentos mediante los cuales quede asegurada la posibilidad real y efectiva de los individuos de alcanzar tal finalidad a través del proceso. Solamente de esa manera los individuos alcanzarán la confianza necesaria en el sistema para que sean desterradas definitivamente las formas autónomas de solución de controversias [...]. Estas reglas que, a su vez, constituyen principios generales de la justicia, al ser aplicados de manera general a través del proceso, se tornan en pieza fundamental del Estado de Derecho. A partir de la efectiva observancia de los mismos las personas podrán alcanzar y cautelar el ejercicio de la libertad a la que tienen derecho así como el respeto de su personalidad que se traduce en los denominados "Derechos Fundamentales» [la cursiva es nuestra]». 
de la interposición del hábeas corpus contra resoluciones judiciales que vulneran el debido proceso legal o la tutela judicial efectiva.

Con mucho acierto, Víctor Obando Blanco ${ }^{11}$ sustenta:

El proceso es un instrumento de tutela del derecho, de modo que si se desnaturaliza por violación de sus formas esenciales, el instrumento de tutela falla y con él sucumbe inexorablemente el derecho de los justiciables; existe entonces la necesidad de cuidar el proceso.

La vulneración del derecho de defensa, de la pluralidad de instancia, del principio acusatorio o de contradicción, entre otros, ${ }^{12}$ puede, en términos de Obando Blanco, hacer sucumbir inexorablemente el derecho a la libertad personal del imputado.

El debido proceso legal se constituye, así, en el blindaje «impenetrable» de quien debe soportar el peso del Estado en un determinado proceso judicial en general y penal en particular; la vulneración del mismo, y, por ende, la vulneración, amenaza o limitación de la libertad personal, justifica y legitima la utilización del proceso constitucional de hábeas corpus

Ahora bien, si el debido proceso legal y la tutela judicial efectiva integran un conjunto de principios o derechos mínimos que se deben observar en la tramitación de un determinado proceso judicial, es legítimo preguntarse cuáles son esos derechos o principios mínimos.

La conspicua constitucionalista Susana Castañeda Otsu ${ }^{13}$ responde que

[...] la doctrina del Tribunal Constitucional sobre este derecho es variada, pues ha tenido oportunidad de pronunciarse sobre casi todos los derechos que integran el debido proceso, dejando establecido que manejamos el concepto bajo la perspectiva del Derecho Internacional de los Derechos Humanos. En tal sentido sus manifestaciones son las que se encuentran consagradas en las cláusulas abiertas de los

11 Obando Blanco, Víctor Roberto. El derecho a la tutela jurisdiccional efectiva en la jurisprudencia. Lima: Palestra Editores, 2001, p. 60.

12 NAVARRA GARMA, Arturo. "Pretensión nulificante de la cosa juzgada fraudulenta en el proceso civil». En César Castañeda Serrano (comp.). Nulidad de cosa juzgada fraudulenta. 1. a ed. T. II. Lima, 2001, p. 22, dice lo siguiente: "Debido proceso es una institución instrumental en virtud del cual debe asegurarse a las partes en todo proceso (legalmente establecido y que se desarrolle sin dilaciones injustificadas) oportunidad razonable de ser oídas por un tribunal competente, predeterminado por la ley, independiente e imparcial, de pronunciarse respecto de las pretensiones y manifestaciones de la parte contraria, de aportar pruebas lícitas relacionadas con el objeto del proceso y de contradecir las aportadas por la contra parte, de hacer uso de los medios de impugnación consagrados por la ley contra resoluciones judiciales motivadas y conforme a derecho, de tal manera que las personas puedan defender efectivamente sus derechos».

13 Castañeda Otsu, Susana Inés. Op. cit., p. 308. 
arts. $1^{\circ}$ del Pacto Internacional de Derechos Civiles y Políticos, $6^{\circ}$ del Convenio Europeo de Derechos Humanos y $8^{\circ}$ de la Convención Americana de Derechos Humanos, sin dejar de considerar el principio de legalidad previsto en estos tres instrumentos, al igual que las reglas específicas relativas a los privados de libertad, en las que se consagran derechos que forman parte del debido proceso: plazo razonable de la detención, derecho a ser informado de las causas de la detención, de la acusación formulada en su contra, del derecho efectivo a obtener reparación, entre otros.

El último párrafo del artículo 4 del CPCL recoge los elementos constitutivos de la tutela procesal efectiva:

[...] se entiende por Tutela Procesal Efectiva aquella situación jurídica de una persona en la que se respetan, de modo enunciativo, sus derechos de libre acceso al órgano jurisdiccional, a probar, de defensa, al contradictorio e igualdad sustancial en el proceso, a no ser desviado de la jurisdicción predeterminada ni sometido a procedimientos distintos de los previstos por la ley, a la obtención de una resolución fundada en derecho, a acceder a los medios impugnatorios regulados, a la imposibilidad de revivir procesos fenecidos, a la actuación adecuada y temporalmente oportuna de las resoluciones judiciales y a la observancia del principio de legalidad procesal penal.

Ahora bien, no obstante que parecería que dicho artículo establece un númerus clausus de los derechos y garantías que integran ese derecho macro denominado tutela procesal efectiva, sin embargo, la interpretación del mismo debe estar acorde con los instrumentos internacionales de derechos humanos y con los tribunales internacionales de derechos humanos. ${ }^{14}$

En tal sentido, la vulneración de cualquier elemento del debido proceso legal o la tutela judicial efectiva, en tanto impliquen la vulneración, amenaza o limitación de la libertad personal, justifica la utilización de un proceso constitucional.

\section{El hábeas corpus contra resoluciones judiciales en el CPCL}

El CPCL, cuya virtud consiste en sistematizar y reunir en un solo cuerpo normativo todos los procesos constitucionales, trae consigo una serie de

14 Al respecto, el artículo $v$ del Título Preliminar del CPCL dice: "El contenido y alcances de los derechos constitucionales protegidos por los procesos regulados en el presente Código deben interpretarse de conformidad con la Declaración Universal de Derechos Humanos, los tratados sobre derechos humanos, así como de las decisiones adoptadas por los tribunales internacionales sobre derechos humanos constituidos según tratados de los que el Perú es parte». 
incorporaciones y/o modificaciones que, fundamentalmente, responden, como no podría ser de otra manera, a las «nuevas» situaciones de hecho que existen en la sociedad.

Tal como lo hemos manifestado, tanto la doctrina como la jurisprudencia fueron dándole contenido y límites a lo que se conoce como un proceso regular, y, por lo tanto, susceptible de ser remediado, al interior del mismo, con los medios de impugnación naturales en dicho proceso; al mismo tiempo, y como consecuencia lógica de ello, se definió lo que debe entenderse por proceso irregular y los parámetros para la postulación del hábeas corpus, a fin de remediar dicha irregularidad.

La ley 23506, y su complementaria, no establecía de manera expresa la procedencia del hábeas corpus contra resoluciones judiciales emanadas de un proceso irregular. ${ }^{15}$ No obstante ello, tal omisión no fue impedimento para que la doctrina y la jurisprudencia encaucen tal instrumento jurídico para atacar resoluciones judiciales en determinados supuestos, tal como ha sido explicado.

La realidad social y la necesidad de responder a la misma hicieron que el CPCL tenga un dispositivo expreso para la procedencia del hábeas corpus contra resoluciones judiciales.

\section{El artículo 4 del CPCL}

En su parte pertinente, este artículo dice: «El hábeas corpus procede cuando una resolución judicial firme vulnera en forma manifiesta la libertad individual y la tutela procesal efectiva».

Los elementos que constituyen la procedencia del hábeas corpus contra resoluciones judiciales se encuentran establecidos de manera clara y precisa: 1) firmeza de la resolución, 2) vulneración manifiesta y 3) vulneración de la libertad individual y de la tutela procesal efectiva.

La libertad individual y la tutela procesal efectiva ${ }^{16}$ han sido analizadas líneas arriba, por lo que en adelante nos referiremos brevemente a los otros elementos de dicha norma.

15 Salvo el caso del artículo 5 de la ley 23506 cuando dice: "Las acciones de garantía también son procedentes si una autoridad judicial, fuera de un procedimiento que es de su competencia, emite una resolución o cualquier disposición que lesione un derecho constitucional».

16 El Tribunal Constitucional ha señalado que los términos «debido proceso legal» y «tutela procesal efectiva» son sinónimos; así, en la sentencia 1076-2003-HC/TC, refiriéndose al juez predeterminado por ley, expresó lo siguiente: "Dicho derecho es una manifestación del derecho al "debido proceso legal» o lo que, con más propiedad, se denomina también "tutela procesal efectiva" [...]». En <http://www.tc.gob.pe/jurisprudencia/2003/ 1076-2002-HC.html>. 


\section{Resolución judicial firme}

Una resolución es firme cuando contra la misma no procede ningún medio impugnatorio. En ese sentido, Anibal Quiroga León, ${ }^{17}$ al referirse a la cosa juzgada, dice: «Sus tres principales características están definidas por la inimpugnabilidad, la inmutabilidad y la coercibilidad. Por la primera se entiende la firmeza de un fallo judicial que impida su revisión [el subrayado es nuestro]».

En ese sentido, para la procedencia del hábeas corpus contra resoluciones judiciales, es necesario e imprescindible que se agoten, en el proceso judicial respectivo, los medios impugnatorios que contiene cada proceso, a fin de que la anomalía o el procedimiento irregular sean subsanados en el mismo proceso judicial donde se generó.

Con ello, en cierto lapso procesal, se reparan las anomalías o irregularidades procesales con el procedimiento irregular. ${ }^{18}$ En efecto, en cierto estadio procesal contra ambos deben proceder, en primer lugar, los medios impugnatorios naturales de cada proceso, con el objeto de ser remediada una anomalía o el procedimiento irregular; en un segundo plano, recién existiría una diferencia cualitativa entre ambos, puesto que solo podrán ser objeto de un proceso constitucional aquellos procedimientos irregulares que vulneran la tutela procesal efectiva y la libertad individual, contenidas en una resolución judicial firme.

Esta exigencia puede ser loable para evitar la carga procesal constitucional y el uso indiscriminado y abusivo de los procesos constitucionales; sin embargo, desde el punto de vista de la realización efectiva de los derechos fundamentales, dicha postura evidencia un margen de desprotección, con lo cual se evidencia que primero se prioriza que no sea abultada la carga procesal frente a la protección de los derechos fundamentales.

Así, por ejemplo, si en un proceso penal se emite un auto de abrir instrucción que ordena la detención sin una fundamentación adecuada, se interpondrá recurso de apelación, con el peligro de que el mismo sea declarado improcedente; luego, se recurre en queja entonces, esperar que la Sala declare procedente la queja y, por lo tanto, suba el incidente de apelación. Tal vez exageramos pero, en ese interín, pueden transcurrir ochos días, hasta

QUiROGa LEÓN, Aníbal. Op. cit., p. 73.

18 SAÉNZ DÁVAlos, Luis. Op. cit., p. 138, dice que «no es lo mismo el Ilamado procedimiento irregular, que la simple anomalía cometida dentro del proceso, por el contrario, regular. En efecto, la irregularidad o simple anomalía procesal, como lo podría ser un proveído incorrecto, una equivocada notificación, la inobservancia de un plazo no gravitante, es esencialmente un error judicial de poca o escasa trascendencia». 
que la resolución que ordena la detención adquiera firmeza; recién en este instante podemos recurrir al proceso constitucional. Mientras tanto, el afectado "tendrá que seguir esperando», detenido en un centro penitenciario.

El perjuicio que puede significar que en determinados casos concretos se tenga que esperar la firmeza de la resolución, a fin de poder recurrir a un proceso constitucional, se evidencia claramente cuando se busca, primero, evitar la excesiva carga procesal constitucional, antes que la protección inmediata y eficaz del derecho fundamental a la libertad del imputado.

La crítica que estamos haciendo a la exigencia del carácter firme de la resolución adquiere mayor relevancia cuando se tiene en cuenta el siguiente elemento de la norma procesal constitucional que se debe analizar.

\section{Vulneración en forma manifiesta}

La vulneración debe ser en forma manifiesta. Según Guillermo Cabanellas, esta palabra significa lo "evidente ${ }_{2}$ indudable, patente.// Claro.//Descubierto.//Innegable.//Visible [el subrayado es nuestro]». ${ }^{19}$

Ahora bien, si la vulneración es manifiesta, evidente, indudable, ¿por qué esperar entonces que la resolución adquiera firmeza para poder acudir a la vía constitucional?

Si hay una detención sin ninguna motivación y argumento, ¿por qué esperar el tramite impugnatorio al interior del proceso?, ¿por qué no acudir directamente a la inmediatez y eficacia del proceso constitucional?

En todo caso, cabría esperar el carácter firme de la resolución que vulnera la tutela procesal efectiva y la libertad personal, siempre y cuando esta vulneración no sea evidente, indudable e innegable, ${ }^{20}$ que no es el supuesto descrito por la norma.

19 Cabanellas, Guillermo. Diccionario enciclopédico de derecho usual. T. v. Op. cit., p. 295.

20 La práctica procesal penal nos trae a colación el caso de una procesada a quien un juez dictó como caución la suma de S/. 30.000,00 (treinta mil nuevos soles y 00/100 céntimos). Aquella argumentaba que incluso no podría conseguir la fianza personal, con lo cual consideró que dicho monto constituía una arbitrariedad e ilegalidad, no se encontraba fundado en derecho y, amenazaba de manera inminente su libertad personal; por ello inició un proceso constitucional de hábeas corpus. Obviando los detalles, consideramos que aquí no existe una vulneración manifiesta de la tutela procesal efectiva y la libertad personal; por lo tanto, se esperará a que la resolución adquiera firmeza a fin de acudir a un proceso constitucional en el que se dilucide si la misma se encuentra debidamente fundamentada.

Así también, por ejemplo, si un juez dicta una orden de detención teniendo en cuenta solo que la pena por imponerse podría superar los cuatro años de pena privativa de libertad, sin una fundamentación adecuada del peligro procesal y de los elementos probatorios que vinculan al procesado con el hecho delictivo, también en este caso 
Debe observarse que el problema no va por el lado de la eficacia, pues al interior del proceso común existen medios de impugnación igualmente eficaces que el proceso constitucional; el lado cuestionable en cierta medida es la carencia de inmediatez ${ }^{21}$ inherente al proceso constitucional. En efecto, ambos procesos (común y constitucional) pueden ser igual de eficaces, sin embargo, ambos no son igual de inmediatos.

Aquí se observa con claridad lo evidenciado a lo largo de este artículo: la clara prioridad que el legislador otorga a la protección de la carga procesal constitucional en desmedro de la reparación inmediata de la vulneración de un derecho fundamental: la libertad personal.

Teniendo en cuenta que el hábeas corpus tutela un derecho fundamental, cuya protección debe ser incondicional frente a actos arbitrarios, no hay razón para condicionar este proceso al agotamiento de los recursos internos del proceso común (apelación, queja, nulidad, etc.) cuando la vulneración de la tutela procesal efectiva y la libertad individual es manifiesta.

Si la arbitrariedad o ilegalidad que vulnera la tutela procesal efectiva y la libertad individual del imputado es manifiesta, el afectado debe tener expedito el instrumento jurídico más eficaz e inmediato que le permita, en el más breve plazo posible, gozar de su libertad en forma plena. Pensamos que carece de mayores fundamentos y de razonabilidad esperar «unos días más» hasta agotar los recursos al interior del proceso ordinario o común (carácter firme de la resolución), cuando el juez constitucional puede resolver de inmediato una vulneración manifiesta, indudable y patente.

cabría esperar la firmeza de la resolución a fin de acudir al proceso constitucional, por cuanto la vulneración de la tutela procesal efectiva no es manifiesta.

El Tribunal Constitucional, en el expediente 0222-2003-HC, sentenció: «En consecuencia, en el transcurso del proceso penal seguido al beneficiario se ha ido desvaneciendo la suficiencia probatoria que dio origen al mandato de detención [el subrayado es nuestro]» En <http://www.tc.gob.pe/jurisprudencia/2004/0222-2004-HC.html>. Es evidente que el Tribunal Constitucional realizó un análisis de la vulneración de la tutela procesal efectiva (falta de sustento en la resolución que dictó el mandato de detención) que no puede ser catalogada como una vulneración manifiesta, indudable, patente. Es lógico que en un caso similar también se debe esperar que la resolución adquiera firmeza a fin de acudir al proceso constitucional.

21 El artículo 30 del CPCL señala: "Tratándose de cualquiera de las formas de detención arbitraria y de afectación de la integridad personal, el Juez resolverá de inmediato. Para ello, podrá constituirse en el lugar de los hechos, y verificada la detención indebida ordenará en el mismo lugar la libertad del agraviado [el subrayado es nuestro]». 


\section{El hábeas corpus no solo debería proceder contra resoluciones judiciales firmes}

Como hemos manifestado anteriormente, si bien la exigencia del carácter firme de la resolución que vulnera la libertad individual es loable desde que pretende evitar la excesiva carga procesal constitucional de los magistrados, sin embargo, dicha exigencia no debe ser interpretada de manera cerrada, de forma que perjudique, en determinadas situaciones concretas, al ciudadano que sufre una vulneración, amenaza o limitación de su libertad personal.

Lo que estamos postulando no es una discusión bizantina, ajena a las consecuencias prácticas. La interpretación literal del artículo 4 del CPCL en el sentido de que el hábeas corpus procede contra resoluciones judiciales firmes en determinados casos concretos trae consigo una indefensión para obtener resultados inmediatos ${ }^{22}$ y efectivos respecto de la tutela de derechos fundamentales como la libertad personal del imputado.

No obstante lo expuesto, entre la libertad personal del imputado o la carga procesal constitucional, es evidente que la inclinación debe ser hacia la más inmediata y eficaz protección de la libertad personal del procesado; por ello, aun cuando se corre el riesgo de una abundante carga procesal constitucional, sin embargo, la vulneración manifiesta de la libertad personal por cualquier medio (una resolución judicial en este caso) requiere del instrumento jurídico más eficaz, inmediato, sencillo y rápido. Esto es lo que el Tribunal Constitucional, en el expediente 697-200-HC, ${ }^{23}$ entendió cuando, en salvaguarda de un derecho fundamental, como es la libertad personal, expresó que «en tales circunstancias es obvio que hacer prevalecer el derecho de todo individuo a ser juzgado en un plazo razonable, es una forma de anteponer la persona al Estado, tal y cual lo proclama la Constitución [el subrayado es nuestro]».

Con el mismo argumento de razonabilidad que se desprende de dicho pronunciamiento, podemos expresar que, ante una vulneración manifiesta de la libertad personal mediante una resolución judicial, no hay por qué anteponer el interés del Estado (evitar la carga procesal constitucional) frente

22 Creemos que la característica esencial que diferencia al proceso constitucional del proceso común es la inmediatez en la obtención del resultado en la tutela de la libertad del imputado. En efecto, no podemos decir que la diferencia esencial es la efectividad, por cuanto el proceso común, con sus respectivos medios de impugnación, es tan eficaz como un proceso constitucional. Por ejemplo, la revocatoria de mandato de detención dictado con manifiesta vulneración de la tutela procesal efectiva bien se puede obtener en el proceso común, bien en el proceso constitucional; sin embargo, en ambos, el resultado no se obtiene con la misma rapidez o inmediatez.

23 En Dialogo con la Jurisprudencia, año 7, n. ${ }^{\circ}$ 30, marzo, 2001, p. 129. 
al interés del afectado: utilizar el medio más eficaz, inmediato, rápido y sencillo que pueda hacer cesar la vulneración, amenaza o limitación de su libertad.

No obstante lo expuesto, es oportuno expresar que el carácter manifiesto de la vulneración de la tutela procesal efectiva y de la libertad personal no es el único supuesto, a nuestro criterio, en el que se debe prescindir del carácter firme de la resolución.

También habrá otras situaciones, como el caso fortuito o fuerza mayor, que impidan la interposición de los recursos pertinentes al interior del proceso. La práctica procesal penal nos ha enseñado que, por ejemplo, la huelga de los trabajadores del Poder Judicial es una situación que impide la interposición de los recursos pertinentes para cuestionar la validez de una resolución judicial que vulnera la tutela procesal efectiva y la libertad personal. Conocimos de cerca el caso de un procesado a quien se le había dictado impedimento de salida del país en un proceso penal por un delito cuya pena máxima era dos años; sin entrar en mayores detalles, podemos decir que dicha medida era totalmente arbitraria, más aún teniendo en cuenta que dicho procesado vive y labora en el extranjero. El procesado, debido a la huelga, se vio ante la imposibilidad de interponer cualquier medio de impugnación y tuvo que esperar el termino de la huelga (cincuenta días aproximadamente) para que, por lo menos, se le suspenda dicha medida y así poder retornar a su trabajo en el extranjero.

En casos como este, es evidente que el juez constitucional no puede resolver la no procedencia del proceso de hábeas corpus por esperar que la resolución que viole la tutela procesal efectiva y la libertad personal previamente adquiera firmeza. Una respuesta como esta ante un problema tan cierto, concreto y nocivo para la libertad del imputado carecería de razonabilidad y de lógica.

Otro de los supuestos donde no se debería esperar el carácter firme de la resolución que vulnera la tutela procesal efectiva y la libertad personal es aquel en el que, no obstante la utilización de los medios impugnatorios al interior del proceso, estos no son resueltos en el plazo establecido por la ley o dentro de un plazo razonable. Estando en juego la vulneración, amenaza o limitación de la libertad personal, los medios de impugnación destinados a atacar a la misma deben ser resueltos dentro del plazo establecido por la norma o en un plazo razonable; lo contrario sería una muestra de desinterés, falta de diligencia o incapacidad del Estado por atender situaciones de suma urgencia, cuyas consecuencias (retardo en la solución) no pueden ser cargados al afectado. 


\section{Nuestra propuesta legislativa}

Teniendo en cuenta lo expuesto, proponemos que el artículo 4 del CPCL sea redactado de la siguiente manera:

El Habeas Corpus procede contra resoluciones judiciales firmes que vulneran la Tutela Procesal Efectiva y la libertad personal. El carácter firme de la resolución no es exigible en los siguientes casos:

1.- Cuando la vulneración es manifiesta, indudable, patente, innegable;

2.- En caso fortuito o de fuerza mayor que hagan imposible la interposición de los recursos pertinentes al interior del proceso judicial donde se dictó la resolución;

3.- Cuando no se observen los plazos establecidos por la ley o un plazo razonable para resolver los recursos interpuestos contra la resolución que vulnera la Tutela Procesal Efectiva y la libertad personal.

Pensamos que esta propuesta responde a la relevancia e importancia de la libertad individual y del daño irreparable que puede causar su vulneración, amenaza o limitación de no ser resuelto con la inmediatez que el caso amerita; por ello, el imputado debe contar con los instrumentos jurídicos necesarios que le permitan, de manera inmediata y eficaz, hacer frente a los actos arbitrarios que le impiden gozar plenamente de su libertad individual. ${ }^{24}$

Por ello, ese instrumento inmediato y eficaz, cual es el proceso constitucional de hábeas corpus, se encuentra consagrado, incluso, en los instrumentos internacionales de derechos humanos. Así, por ejemplo, el artículo 25.1 de la Convención Americana de Derechos Humanos nos dice:

Toda persona tiene derecho a un recurso sencillo y rápido o a cualquier otro recurso efectivo ante los jueces o tribunales competentes, que la ampare contra actos que violen sus derechos fundamentales reconocidos por la Constitución, la ley o la presente Convención, aún cuando tal violación sea cometida por personas que actúen en ejercicio de sus funciones oficiales [la cursiva es nuestra].

24 Castañeda Otsu, Susana. Op. cit., p. 273, citando a Ramón Soriano, dice: «Cabe preguntarse si la libertad personal, debe ser protegida de manera diferenciada respecto de los demás derechos. Siguiendo a Ramón Soriano la respuesta es afirmativa, ya que la libertad personal conocida también como libertad individual, libertad física, libertad de movimiento o libertad deambulatoria, es una manifestación básica de la libertad, de mayor excelencia que otro tipos de libertad (expresión, de reunión, de tránsito, etc.) cuya violación es difícilmente reparable y que por lo mismo debe ser especialmente contemplada por el Derecho y sus instrumentos procesales». 
Siguiendo esta tendencia, el Tribunal Constitucional, citando la opinión consultiva OC/8/87 de la Corte Interamericana de Derechos Humanos, dice: ${ }^{25}$

La Comisión [sic] Interamericana de Derechos Humanos ha equiparado el derecho al recurso sencillo, rápido y efectivo con los procesos de amparo y habeas corpus (Opinión Consultiva OC/8/87, párrafo 32). De esta forma, de consuno, tanto el ordenamiento constitucional como el ordenamiento supranacional regional reconocen el derecho constitucional a la protección judicial de los derechos fundamentales. Protección judicial a la que se debe promover su acceso, aun si los actos que ocasionan agravo de los derechos constitucionales son expedidos «por personas que actúen en el ejercicio de sus funciones oficiales», dentro de los cuales, naturalmente, se encuentran comprendidos los jueces [el subrayado es nuestro].

\section{Conclusiones}

\section{Primera conclusión}

En la ley 23506 y su ley complementaria, el proceso constitucional de hábeas corpus procedía ante un proceso irregular por interpretación a contrario sensu de los artículos pertinentes; sin embargo, a efectos de la procedencia del hábeas corpus, dicho proceso irregular debía estar directamente vinculado con la vulneración de las garantías constitucionales mínimas (debido proceso legal y tutela judicial efectiva) y, a su vez, la vulneración de los mismos debía implicar la vulneración, amenaza o limitación de la libertad personal; así lo llegó a establecer la jurisprudencia del Tribunal Constitucional y la doctrina.

\section{Segunda conclusión}

Cuando la vulneración de la tutela procesal efectiva y la libertad individual del imputado, contenida en una resolución judicial, es manifiesta, evidente patente e indudable no se debe esperar que dicha resolución adquiera firmeza para acudir a un proceso constitucional de hábeas corpus.

\section{Tercera conclusión}

El carácter firme de la resolución que vulnera la tutela procesal efectiva y la libertad personal no debería ser exigible en caso de que la vulneración sea

25 En <http://www.tc.gob.pe/jurisprudencia/2002/1230-2002-HC.html>. 
manifiesta, cuando por caso fortuito o fuerza mayor sea imposible interponer los recursos pertinentes al interior del proceso o cuando, no obstante haber interpuesto los recursos impugnatorios, estos no sean resueltos en el plazo previsto por la norma o dentro de un plazo razonable. 